\title{
Tissue distribution, metabolism and hepatic tissue injury in Chinese lizards (Eremias argus) after a single oral administration of lambda- cyhalothrin ${ }^{\text {t3 }}$
}

\author{
Jing Chang ${ }^{\text {a, b }}$, Jitong Li ${ }^{\text {a, b }}$, Huili Wang a , Yinghuan Wang a, Baoyuan Guo a, Jing Yin a, b, \\ Weiyu Hao ${ }^{\text {a, b}}$, Wei Li ${ }^{\text {a }}$, Jianzhong $\mathrm{Li}^{\mathrm{a}}$, Peng $\mathrm{Xu}^{\text {a, * }}$ \\ a Research Center for Eco-Environmental Sciences, Chinese Academy of Sciences, Shuangqing RD 18, Beijing 100085, China \\ ${ }^{\mathrm{b}}$ University of Chinese Academy of Sciences, Yuquan RD 19 a, Beijing, 100049, China
}

\section{A R T I C L E I N F O}

\section{Article history:}

Received 30 May 2016

Received in revised form

16 August 2016

Accepted 17 August 2016

Available online 25 August 2016

\section{Keywords:}

Lizard

Lambda-cyhalothrin

Distribution

Metabolism

Histopathology

\begin{abstract}
A B S T R A C T
Lambda-cyhalothrin (LCT) is a widely used pyrethroid with neurotoxicity. However, little is known about the toxicokinetics of LCT in reptiles. In this study, the absorption, distribution, metabolism and excretion of LCT in Chinese lizards (Eremias Argus) were determined following a single dose (10 mg kg-1) treatment. In the liver, brain, gonads and skin, LCT levels peaked within several hours and then decreased rapidly. However, the concentration of LCT gradually increased in the fat tissue. More than $90 \%$ of the LCT dose was excreted in the faeces. One LCT metabolite, 3-phenoxybenzoic acid (PBA), was detected in lizard plasma and tissues. PBA preferentially accumulates in the brain and plasma. The half-life of PBA in the brain was 3.2 days, which was 35.4-fold greater than that of LCT. In the plasma, the concentration of PBA was significantly higher than that of LCT. The bioaccumulation of LCT in tissues was enantioselective, and the enantiomeric fractions (EF) ranged from 0.72 to 0.26 . The preferential accumulation of enantiomers changed according to exposure time, but the reasons behind this phenomenon were not clear. For pathological analysis, vacuolation of the cytoplasm and large areas of necrosis were observed in the liver sections after $168 \mathrm{~h}$ of dosing. The liver tissues exhibited both decreases in the hepatosomatic index and histopathological lesions during the exposure period. In this study, the effect concentration of LCT in lizards was 200 -fold lower than its $\mathrm{LD}_{50}$ value used in risk assessments for birds. These results may provide additional information for the risk assessment of LCT for reptiles and indicate that birds may not be an ideal surrogate for reptile toxicity evaluation.
\end{abstract}

(C) 2016 Elsevier Ltd. All rights reserved.

\section{Introduction}

Synthetic pyrethroids (SPs) are used to control a wide range of insect pests for a variety of crops (Alonso et al., 2012) and have become a major class of pesticides used against pests as a replacement for more toxic organophosphorous insecticides (Katsuda, 1999).

SPs contain 1-3 asymmetric positions, making them a family of chiral insecticides with a large number of stereoisomers (PerezFernandez et al., 2010). The enantiomers show different bioavailability and toxicity effects in organisms. For instance, the oestrogen

\footnotetext{
This paper has been recommended for acceptance by Charles Wong.

* Corresponding author.

E-mail address: pengxu@rcees.ac.cn (P. Xu).
}

response of Japanese medaka to $1 S$-cis-bifenthrin was approximately 123 times greater than that to the $R$ enantiomer, which preferentially accumulates in the liver and other tissues (Wang et al., 2007). Under field conditions, enantioselective degradation was also observed for cis-bifenthrin, permethrin and cyfluthrin (Qin et al., 2006). SPs are organic contaminants with high hydrophobicity and low water solubility ( $\log K_{o w}>5$ ). For this reason, this group of insecticides tends to be rapidly sorbed by soil (Chang et al., 2016) or distributed preferentially into lipid-rich internal tissues, especially brain and fat tissues (Soderlund et al., 2002). In that case, SPs may bioaccumulate in non-target organisms at higher trophic levels and cause toxic effects. In addition, SPs have caused histopathological alterations in different animal tissues, including liver (Li et al., 2014), testis (Al-Sarar et al., 2014) and kidney (Li et al., 2014) tissues.

Although SPs have a tendency to accumulate in living organisms 
because of their non-polar properties, the bioaccumulation may be mitigated by their metabolism. Most SPs contain a phenoxybenzyl group and are converted to 3-phenoxybenzyl alcohol by carboxylesterase followed by oxidation to a 3-phenoxybenzaldehyde and finally to 3-phenoxybenzoic acid (PBA) (Fig. S1) (Nakamura et al., 2007). PBA is regarded as a common metabolite form or intermediate (Shan et al., 2004). Monitoring PBA levels could provide an indication of parent compound metabolism (Leng and Gries, 2005). PBA can be detected in the plasma of rats (Ding et al., 2004), in soil (Chang et al., 2016) and even in human urine (Shan et al., 2004). Compared to its parent compound, PBA has a smaller molecule weight, stronger polarity and faster migration within the environment (Deng et al., 2015).

Most toxicokinetic and toxicodynamic studies of SPs have been conducted on fish (Tu et al., 2014). The bioconcentration factors (BCFs) of SPs in fish are approximately 360-6000 (Laskowski, 2002). However, data regarding the bioaccumulation of SPs in reptiles are scarce. Lambda-cyhalothrin (LCT) is a typell SP (Fig. S1). Our previous study demonstrated that the elimination rate of LCT in earthworms was lower than that of bifenthrin (Chang et al., 2016). Weir et al. (2015) recently found LCT to be more acutely toxic to Western fence lizards than avians (Weir et al., 2015). Little is known about the toxicokinetics of LCT in reptiles.

Reptiles are essential for ecological balance and comprise $28 \%$ of known vertebrate species (Sparling et al., 2010). World-wide population declines in reptiles have been noted (Gibbons et al., 2000). The contribution of environmental contaminants, especially pesticides, to reptile decline has not been well-addressed (Wagner et al., 2015). Several studies have focused on the toxic effects of metals in turtles (Meyer et al., 2014) or conducted ecological risk assessment of industry chemicals on lizards (Weir et al., 2014). As little information on reptilian ecotoxicology is available, birds are often used, perhaps inappropriately, as surrogates in risk assessment (Weir et al., 2015). It is essential to obtain toxicokinetic data for the absorption, distribution, metabolism and excretion of pesticides in reptiles. Kinetic profiling information will improve risk assessment in reptiles.

Lizards have been proposed as an ideal model to assess the toxic effects of pollutants on reptiles (Amaral et al., 2012). Lizards are characterized by their small size, short maturation periods and easy breeding in laboratory conditions (Aguilera et al., 2012). In addition, lizards are mostly insectivorous and are frequently exposed to pesticides.

The aim of this study was to evaluate the toxicokinetic profile and histopathology of SPs in reptile organisms using LCT as a representative SP and the Chinese native lizard Eremias argus (E. argus) as a model.

\section{Materials and methods}

\subsection{Chemicals}

LCT ( $\geq 98 \%$ purity) and PBA ( $\geq 98 \%$ purity) were provided by J\&K Chemical Technology (Beijing, China). Acetonitrile, methanol and n-hexane (HPLC grade) were obtained from Dikma (Beijing, China). All other chemicals and solvents were analytical grade and purchased from commercial sources (Table S1).

\subsection{Test lizards and husbandry}

Due to the potential variability in dosage associated with vitellogenesis and egg production, females were not included in the exposure experiment. The 2-3-year-old mature E. argus animals were purchased from GuanYuan flower bird fish and insect market (Beijing, China). The body weights were $3.2-4.5 \mathrm{~g}$, and the body length from the bottom of neck to anus was greater than $45 \mathrm{~mm}$. The lizards were kept in $5.0 \times 1.2 \times 0.4 \mathrm{~m}$ solid bottom indoor aquariums covered with $10 \mathrm{~cm}$ mollisol and fallen leaves. Ultraviolet lamps were set on $12 \mathrm{~h}$ light/dark cycles to provide enough light and maintain the needed temperature. The temperature and humidity were maintained at $25-30{ }^{\circ} \mathrm{C}$ and $30-50 \%$, respectively. The lizards were fed with live mealworms twice a day. Water was sprayed several times a day, and animal excreta were removed every other day.

\subsection{Uptake experiment}

No direct toxicity data for LCT in reptiles exist and birds are usually used as surrogates in risk assessment (Weir et al., 2010). The $\mathrm{LD}_{50}$ value of LCT in birds is greater than $2000 \mathrm{mg} \mathrm{kg}^{-1}$, and $0.5 \%$ of the $\mathrm{LD}_{50}$ value was selected in this study. The exposure concentration for lizards was $10 \mathrm{mg} \mathrm{kg}^{-1}$ body weight (bw).

Lizards were administered LCT orally for quantitative analysis. To ensure that the corn oil was homogenously mixed with LCT, the dosing method was set up in steps (Suski et al., 2008; McFarland et al., 2012). LCT was first dissolved in methanol and then dispersed into the corn oil (methanol/oil $=1 / 9, \mathrm{v} / \mathrm{v}$, total volume $20 \mathrm{~mL}$ ). Before dosing, the corn oil-methanol lactescence was mixed continually on a magnetic stirring apparatus. The micro injector was used to inject a volume of 5-10 $\mu \mathrm{L}$ lactescence into the oral cavities of the lizards.

Prior to the experiments, each group was allowed to acclimate to the experimental conditions for one week in experimental glass cages $(60 \times 60 \times 40 \mathrm{~cm})$. Male lizards were randomly divided into four groups including the control group $(n=6)$ and treatment groups (total 3 groups, each group $n=16$ ). Lizards were given oral administration of one dose of $10 \mathrm{mg} \mathrm{kg}^{-1} \mathrm{bw}$ LCT or corn oil. Lizards in the treatment groups were euthanized at 1, 3, 6, 12, 24, 72, 120, and $168 \mathrm{~h}$ after oral exposure. In the preliminary experiment, lizards in the control group were sacrificed after 6 h, $72 \mathrm{~h}$ and $168 \mathrm{~h}$ exposure. No differences were found among the different exposure times. In the final experiment, lizards in the control group were sacrificed only at $168 \mathrm{~h}$. The lizards euthanized at $168 \mathrm{~h}$ after LCT exposure were put in a separate cage for excretion collection. Two lizards were selected randomly from each group, and three replicate were prepared at each time point. Blood was immediately centrifuged to separate the plasma and the brain, heart, kidney, gonads, liver, skin, and fat were collected (the fat was collected from the bottom of the abdomen, close to the hindquarters). The tissue samples were weighed and frozen at $-20^{\circ} \mathrm{C}$.

\subsection{Chemical analysis}

For analysis of these samples, plasma or homogenized tissues (tissues from two lizards were used for each replicate) were mixed with $15 \mathrm{~mL}$ of acetonitrile in a $25 \mathrm{~mL}$ polypropylene centrifuge tube. Trifluoroacetic acid $(15 \mu \mathrm{L})$ was added for the metabolite extraction as well as the inhibition of LCT metabolism. The tube was vortexed for $2 \mathrm{~min}$, ultrasound extracted for $10 \mathrm{~min}$, and then centrifuged at $5867 \times \mathrm{g}$ for $5 \mathrm{~min}$. The supernatant was transferred to a roundbottom flask. The extraction was repeated again following the same method and then combined with the upper phase. The upper layer was filtered through $5 \mathrm{~g}$ of anhydrous sodium sulfate for dehydration and evaporated to dryness on a vacuumed rotary at $45^{\circ} \mathrm{C}$. The residue was redissolved in $1 \mathrm{~mL}$ of $\mathrm{n}$-hexane and filtered through a $0.22-\mu \mathrm{m}$ filter prior to analysis on GC/MS/MS. For the analysis of PBA on LC/MS/MS, the sample was evaporated to dryness and then redissolved in acetonitrile.

A Thermo-TSQ 8000 GC/MS/MS equipped with an electronimpact ionization (EI) source was used for the quantitative 
analysis of LCT in samples. A TR-35MS column $(0.25 \mathrm{~mm} \Phi \times 30$ $\mathrm{mID} \times 0.25 \mu \mathrm{m}$, THERMO) was used for the racemate analysis. LCT enantiomer separation was achieved on a chiral capillary BGB-172 column (20\% tert-butyldimethylsilyl- $\beta$-cyclodextrin dissolved in 15\% diphenyl-polysiloxane and 85\% dimethyl-polysiloxane, GBG Analytik, Adliswil, Switzerland). The chiral column was held at $180^{\circ} \mathrm{C}$ for $2 \mathrm{~min}$, ramped at $1^{\circ} \mathrm{C} \mathrm{min}^{-1}$ to $210^{\circ} \mathrm{C}$ for $60 \mathrm{~min}$, ramped at $5{ }^{\circ} \mathrm{C} \mathrm{min}^{-1}$ to $230^{\circ} \mathrm{C}$, and then held at $230^{\circ} \mathrm{C}$ for $5 \mathrm{~min}$. The QqQ mass spectrometer was operated in the selected reaction monitoring (SRM) mode, and the parameters were optimised before analysis. The $\mathrm{m} / \mathrm{z} 181.100 \rightarrow 152.100$ was used for quantification with a collision energy of $28 \mathrm{eV}$. The average recoveries for LCT at levels of $0.1,1,10 \mathrm{mg} \mathrm{kg}^{-1}$ ranged between $90 \%$ and $95 \%$ in plasma and tissues ( $\mathrm{n}=3$ for each concentration). Blank plasma and tissue samples (in the control group) were detected, and no target chemicals were found. The limit of detection ( $L O D, S / N=3$ ) for LCT was $0.002 \mathrm{mg} \mathrm{kg}^{-1}$ (chiral column).

The LCT metabolite PBA was detected by LC/MS/MS. LC/MS/MS was performed on a TSQ Quantum AccessMax triple quadrupole MS and an Accela 600 pump/auto sampler HPLC. A $C_{18}$ column was used, and the eluents included acetontrile and formic acidic water $(80: 20, v / v)$ with a flow rate of $200 \mu \mathrm{L} \mathrm{min}{ }^{-1}$. The analytes were detected by multiple reaction monitoring (MRM) mode using negative electrospray ionization mass spectrometry (ESI-MS). The $\mathrm{m} / \mathrm{z} 213.00 \rightarrow 93.25$ and $\mathrm{m} / \mathrm{z} 213.00 \rightarrow 169.18$ were used for confirmation and quantification when the collision energies were set at $30 \mathrm{eV}$ and $16 \mathrm{eV}$, respectively. The LOD for PBA was $0.005 \mathrm{mg} \mathrm{kg}^{-1}$.

\subsection{Histopathological analysis}

When sampled at $168 \mathrm{~h}$ after dosing, a portion of the liver was stored in $4 \%$ paraformaldehyde for histopathological analysis. The methods generally followed those previously described by McFarland et al. (2008) (McFarland et al., 2008). Tissue sections were trimmed, placed in cassettes, and embedded in paraffin. Serial two-micron sections were stained with haematoxylin and eosin and then examined via light microscopy (Olympus DP73).

\subsection{Data analysis}

Tissue somatic indices were calculated as following:

Tissue somatic index $\%=$ tissue weight/body weight $\times 100$

To illustrate the enantioselective bioaccumulation of LCT, the enantiomeric fraction (EF) is generally used. The EF formula is as follows:

$$
E F=\frac{(+)}{(-)+(+)}
$$

The EF value of the racemic mixture is 0.5 , whereas preferential accumulation of $(+)$ or $(-)$ yields $\mathrm{EF}>0.5$ or $<0.5$.
Statistical analysis of the data was performed using one-way ANOVA by SASPAL 3.0 (Hu liangping, China). Values of $p<0.05$ were considered statistically significant. The metabolic kinetics of LCT in different lizard tissues were also analysed using SASPAL 3.0 (Hu liangping, China).

\section{Results and discussion}

\subsection{Mortality, growth, and tissue somatic indices}

No mortality or significant difference in body weight was observed between the control group and the treatment groups during the exposure period. Tissue somatic indices have been widely used as predictors of adverse effects in animals (Li et al., 2009). The tissue somatic indices of the treated and control groups are shown in Table 1. There were no significant differences between the control and treated groups in the gonads, brain, kidney and heart tissues $(p>0.05)$. However, the hepatosomatic index (HSI) in the treated group was significantly less than that of the control group $(p<0.05)$. This phenomenon suggested that the liver was the most vulnerable organ when lizards are exposed to LCT. The liver may be the main detoxification organ in lizards during LCT metabolism. The decreased HIS could directly affect the degree of detoxification and indicate LCT toxicity. This result was also consistent with those reported in a previous study (Chen et al., 2016) in which the lizard liver was more sensitive to cypermethrin exposure than were other tissues.

\subsection{Kinetic degradation of LCT in lizard plasma, tissues and faeces}

Despite their lipophilicity, pyrethroids may not bioaccumulate in tissues because they are readily metabolised by hydrolases and cytochrome-P450-dependent monooxgenases in the liver and other tissues (Crawford et al., 1981). The pharmaceuticals first enter into the blood circulation after intravenous injection (Anadon et al., 2006). However, after oral administration, it was presumed that LCT flowed into the stomach, was absorbed by the intestinal cells due to the large exposed surface area and passed through the gastrointestinal (GI) circulation before entering the blood circulation (Pan et al., 2014). Finally, LCT reached different tissues by passive diffusion. For intestinal absorption and GI circulation, that oral bioavailability was less than that of intravenous administration. The tissue concentration versus time profiles for LCT is shown in Fig. 1. LCT was distributed in almost all tissues, although it was not detectable in the plasma and kidney. The maximal LCT concentration $\left(\mathrm{C}_{\max }\right)$ was reached approximately $1-6 \mathrm{~h}$ after administration. The $C_{\max }$ in each tissue was ranked in the following order: liver, skin, gonads, fat, brain and heart. Combined with the data reported for cypermethrin (Chen et al., 2016), deltamethrin (Anadon et al., 1996) and permethrin (Anadon et al., 1991), it could be predicted that SPs easily penetrate into all tissues.

The highest LCT concentration was found in the liver, which was mainly due to the strong first pass effect (Kanazu et al., 2005; Liu et al., 2010; Ikemura et al., 2009). The liver is regarded as the

Table 1

Growth and tissue somatic indices of lizards after $168 \mathrm{~h}$ exposure to lambda-cyhalothrin (LCT).

\begin{tabular}{llllll}
\hline \multirow{2}{*}{ Group } & Body weight/g & \multicolumn{2}{l}{ Tissue somatic indices (\%) } \\
\cline { 2 - 6 } & & Liver & Gonads & Brain & Kidney \\
\hline Control & $3.76 \pm 0.67$ & $4.03 \pm 0.26$ & $1.00 \pm 0.10$ & $0.80 \pm 0.10$ & $0.68 \pm 0.39$ \\
Treated & $3.96 \pm 0.72$ & $2.92 \pm 0.37^{\mathrm{a}}$ & $0.86 \pm 0.29$ & $0.99 \pm 0.32$ & $0.69 \pm 0.30$ \\
\hline
\end{tabular}

The data are expressed as the mean \pm S.E. of each treatment $(n=6)$

a Statistically significant difference from the control $(p<0.05)$. 

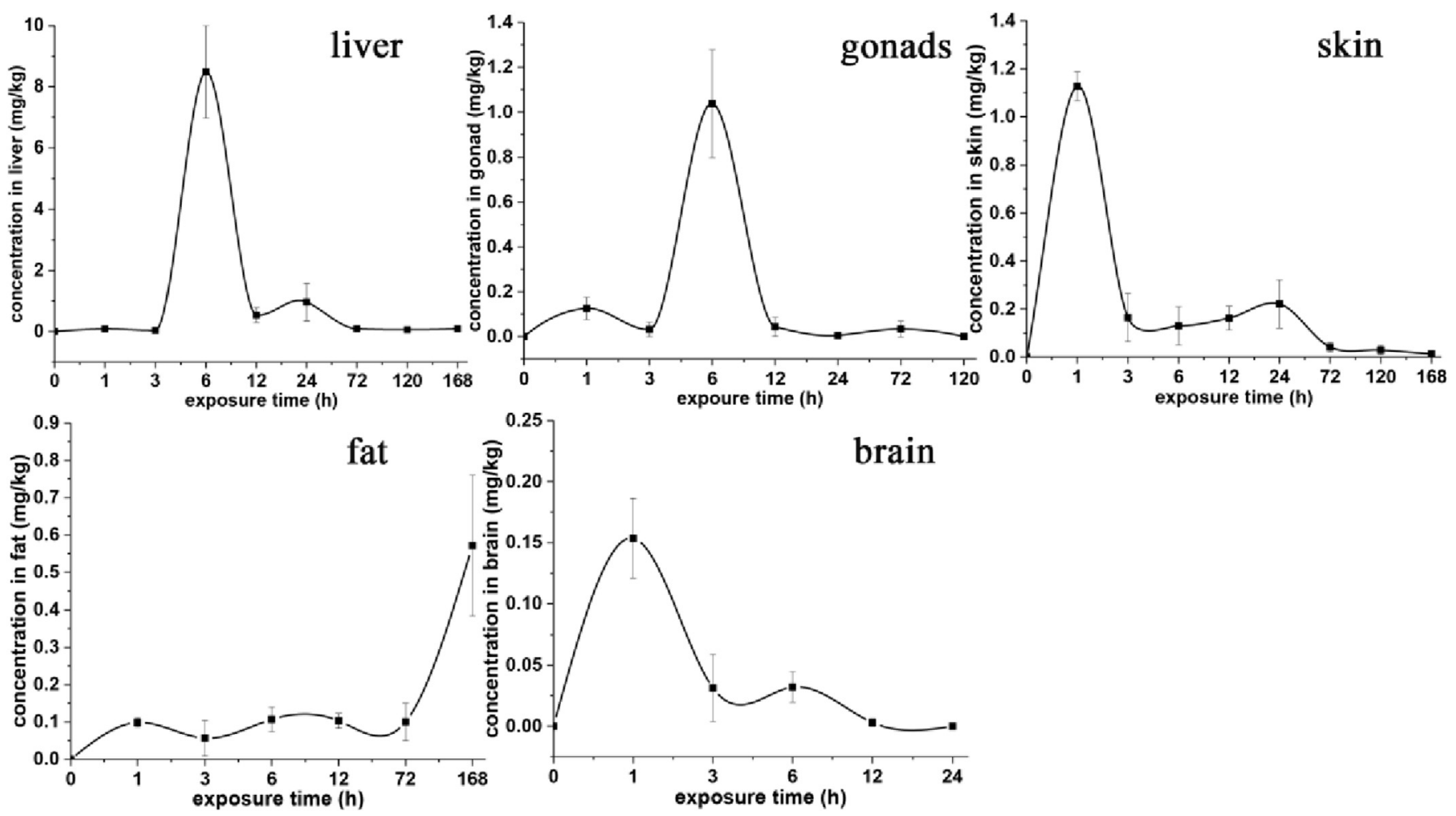

Fig. 1. Tissue concentration-time profiles of oral lambda-cyhalothrin (LCT) administration $\left(10 \mathrm{mg} \mathrm{kg}^{-1}\right)$ in lizards $(\mathrm{n}=3$, mean \pm S.E.).

main detoxification organ, mainly due to its efficient cleavage of ester bonds through hydrolysis, which leads polar metabolites that can be easily excreted following further oxidation (Starr et al., 2014). During the 168-h exposure period, the concentration of LCT in the liver quickly peaked $\left(8.48 \mathrm{mg} \mathrm{kg}^{-1}\right)$ at $6 \mathrm{~h}$ and then began to decrease sharply to $0.09 \mathrm{mg} \mathrm{kg}^{-1}$ at the end of the exposure period. In the liver, the disposition of LCT is best described using a two-compartment model (Table S3). The elimination half-life of LCT was $4.88 \mathrm{~h}$. Previous studies showed that the elimination halflife of LCT was $13.14 \mathrm{~h}$ in the rat liver (Anadon et al., 2006) and $29.88 \mathrm{~h}$ in zebrafish eleuthero embryos (Tu et al., 2014). It was predicted that the lizard liver could eliminate LCT more quickly than could other non-target organisms. Walker and Ronis (1989) have presumed that reptiles may be more susceptible to pesticides than mammals or birds due to their low metabolic rate and simple enzymatic systems, which results in the slow breakdown of deltermethrin in the body (Walker and Ronis, 1989). However, predictive relationships between birds and reptile $\mathrm{LD}_{50}$ were found in another study (Weir et al., 2015). These different conclusions may result from different exposure methods and levels.

In the present study, LCT was accumulated in the fat and rapidly eliminated in the heart and gonads tissues. The concentration of LCT in the heart was just detectable at $3 \mathrm{~h}$ and $6 \mathrm{~h}$. In the gonads, the concentration of LCT showed a similar tendency with that in the liver. The LCT concentration in the fat slowly increased from $0 \mathrm{~h}$ to $72 \mathrm{~h}$ and exhibited a sharp increase thereafter. A previous study showed that the tissue residues of cypermethrin were very low in rats except in the fat (Crawford et al., 1981). Fat was also the major depository after deltermethrin exposure in rats (Kim et al., 2010) or pigs (Pan et al., 2014). The octanol-water partition coefficient ( $\left.\mathrm{K}_{\mathrm{ow}}\right)$ has been widely regarded as a key contributor in the bioavailability of pesticides (Tu et al., 2014). The Log $\mathrm{K}_{\mathrm{ow}}$ of SPs was generally greater than 5 , which suggested that the bioavailability of SPs was high in lipid-rich tissues.
The brain is considered the target organ after SP exposure, which may cause neurotoxicity (Kim et al., 2010). In this study, LCT could cross the blood-brain barrier and cause neurological effects in the lizards. LCT was detected in the brain at $1 \mathrm{~h}$ after oral administration. The elimination of LCT in the brain matched with firstorder kinetics (Table S3). The very low LCT residue in the brain was eliminated at a rate of $7.74 \mathrm{mg} \mathrm{kg}^{-1}$. day ${ }^{-1}$ and was not detectable after $24 \mathrm{~h}$. The LCT levels had a good correlation with motor activity. After $1 \mathrm{~h}$, LCT-induced neurological signs could be observed, including accelerating running, sinuous writhing and whole body tremors, which were consistent with results from a previous study in lizards (Chen et al., 2016). However, these abnormal behaviours disappeared after $24 \mathrm{~h}$ of exposure. In addition, Starr et al. (2014) also found a positive relationship between motor activity and SPs brain concentration in rats (Starr et al., 2014). These results suggested that a dose-effect relationship was apparent in the brain after SP exposure.

The skin can accumulate large amounts of highly lipophilic chemicals (Kim et al., 2008). In the present study, the LCT level in the skin was greatest at $1 \mathrm{~h}$ after exposure and then began to fluctuate at approximately $0.1 \mathrm{mg} \mathrm{kg}^{-1}$ from $3 \mathrm{~h}$ to $72 \mathrm{~h}$. The concentration of LCT finally decreased to $0.01 \mathrm{mg} \mathrm{kg}^{-1}$ at $168 \mathrm{~h}$. LCT may be excreted through the skin or released to the blood circulation again. The lizard skin cannot accumulate LCT at high levels and may be considered as a slow-release depot for LCT in lizards.

The LCT concentration in the plasma was lower than the LOD concentration. The extremely low LCT concentration in the plasma was associated mainly with the following causes: 1) the plasma volume in the lizards was too small; 2) the plasma protein has a high affinity for LCT (Rutten et al., 1993) and induces lower levels of free LCT in plasma; 3 ) extensive metabolism in the blood and liver (Tsai and Tsai, 2004; Hao et al., 2007); and 4) LCT may preferentially accumulate in lipid-rich tissues due to its non-polar properties (Crawford et al., 1981). Gogebakan and Eraslan (2015) suggested 
that the oral bioavailability of permethrin in broiler chicken serum was only 11\% (Gogebakan and Eraslan, 2015). In rats, the deltermethrin concentration in the plasma was also much lower than that in the brain (Kim et al., 2006). These results elucidated that the oral bioavailability of SPs is low in the blood.

The excretion of pharmaceuticals occurred mainly through faeces and urine (Chen et al., 2007). Because LCT was not detected in the kidney, only its level in the faeces was analysed. The LCT concentration in the faeces was $45.0 \mathrm{mg} \mathrm{kg}^{-1}$ within $168 \mathrm{~h}$. This excretion behaviour revealed that more than $90.0 \%$ of the administered dose was excreted in the faeces (Table S4). In contrast, less than $1.7 \%$ of the dosed LCT was distributed in the tissues. The firstpass effect may be an important factor leading to the very low absorption and distribution of LCT in the tissues.

\subsection{LCT metabolite in lizard plasma, tissues and faeces}

Metabolites are important indicators of biological processes, and the quantification of their concentrations may provide important insight into the elimination of pesticides (Prueksaritanont et al., 2006). In addition, some metabolites may be more active or toxic to organisms (Zhang et al., 2014). SP metabolites (e.g., PBA) have been used as the most sensitive biomarker for environmental SP exposure since the late 1990s (Hirosawa et al., 2011). Metabolite formation has been regarded as a detoxification step of LCT because PBA is generally not considered to be neurotoxicant (Starr et al., 2014). However, one study proved that PBA was more toxic to earthworms than the parent compound (Yao et al., 2015). PBA may induce different toxic effects compared with SPs.

The PBA concentration-time profile in different tissues and plasma is shown in Fig. 2. The kinetics of a metabolite generated in vivo is influenced not only by its own properties but also by those of the parent compound (Schumacher, 1981). In this study, the $C_{\max }$ of PBA was ranked in the following order: gonads, kidney, brain, plasma, skin and liver. PBA was not detected in the heart or fat tissue. According to a dose-effect relationship, the relatively high concentration of PBA in the gonads may explain its high antiestrogenic activity (Sun et al., 2014). The gonads concentration of PBA fluctuated greatly during the exposure period. This phenomenon may be explained by the consecutive uptake and elimination processes in the gonads. The highest and lowest levels were 7.16 and $0.91 \mathrm{mg} \mathrm{kg}^{-1}$ in the gonads, respectively. In the kidney, liver and plasma, bimodal phenomena were observed. At the end of exposure, PBA levels in the kidney and plasma were still unstable, whereas the concentration of PBA in the liver reached to a steady point. The $C_{\max }$ of PBA in the kidney was higher than that in the liver. One reason may be the elimination process of hepatic transport and renal reabsorption (Lin, 2006). Another proper explanation was that PBA may be conjugated to amino acids, sulfates, sugars and sugar acids in the liver (Laffin et al., 2010). In addition, as there are more metabolic enzymes in the liver than in the kidney, it was presumed that significant hydroxylation of PBA to $4^{\prime}-\mathrm{OH}-\mathrm{PBA}$ may occur in the liver (Huckle et al., 1981). In the plasma, the $\mathrm{C}_{\max }$ was observed between $12 \mathrm{~h}$ and $24 \mathrm{~h}$. The concentration of PBA $\left(C_{\max }: 1.98 \mathrm{mg} \mathrm{L}^{-1}\right.$ ) was higher than that of LCT, which may be explained by the relatively high metabolic rate of LCT in the plasma. The blood may be another important location for SP metabolism (Lestremau et al., 2014). Another speculation was that the partitioning of LCT and PBA in the plasma based on their physicalchemical properties was different. The concentration of PBA in the skin experienced a relatively stable increase and still fluctuated around $0.3 \mathrm{mg} \mathrm{kg}^{-1}$ at the end of the exposure period. The skin PBA concentration correlated with the plasma PBA concentration. The distribution of PBA in the skin may depend on the concentration of PBA in the plasma.

In the lizard brains, $\mathrm{PBA}$ reached $\mathrm{C}_{\max }$ at $6 \mathrm{~h}$ and then decreased to a relatively stable level at approximately $1.00 \mathrm{mg} \mathrm{kg}^{-1}$. The $\mathrm{t}_{1 / 2}$ of PBA in the brain was 35.4-fold greater than that of its precursor
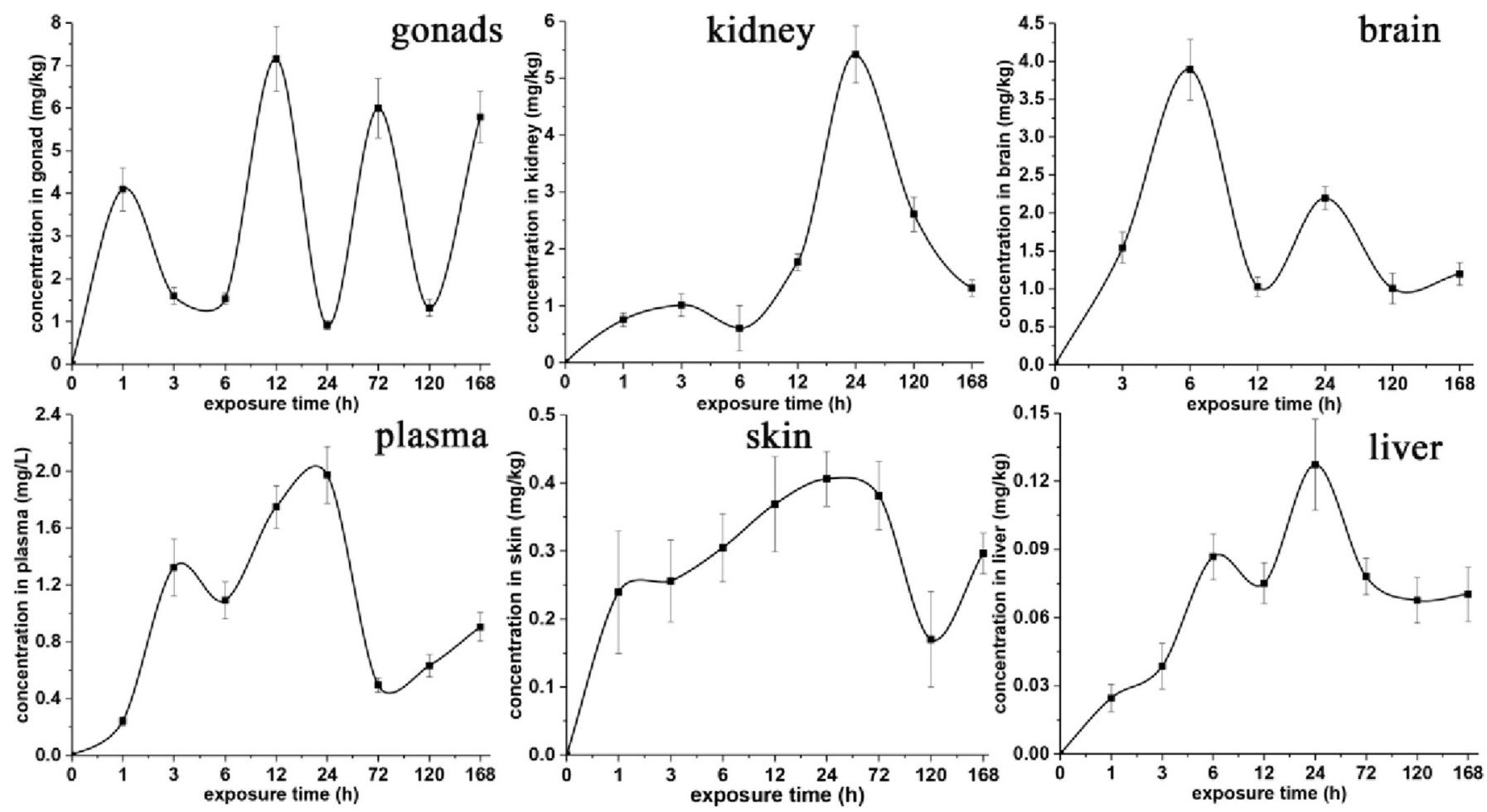

Fig. 2. Plasma and tissue concentration-time profiles of 3-phenoxybenzoic acid (PBA) in lizards $(n=3$, mean \pm S.E.). 

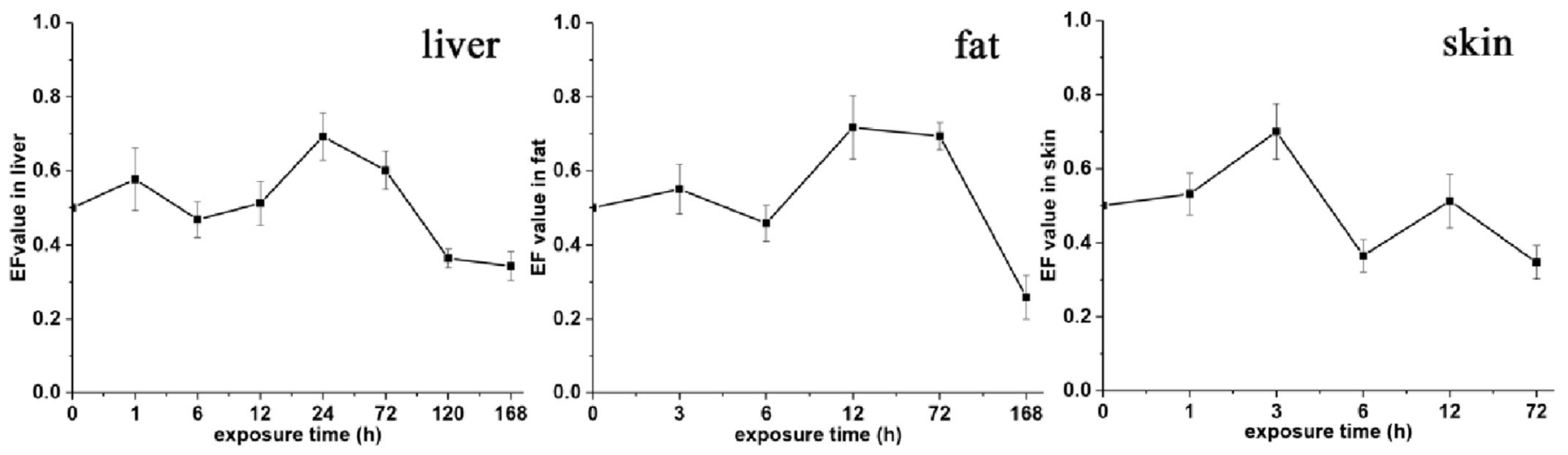

Fig. 3. Enantiomeric fraction (EF) of lambda-cyhalothrin (LCT) in lizard tissues $(n=3$, mean \pm S.E.).

(Table S3). The metabolite formation within the brain may be limited due to the low concentration of LCT. However, penetration through the blood-brain barrier for PBA may be easy. The brain is the dominant organ that regulates the endocrine system, whereas PBA can disturb the endocrine balance (McCarthy et al., 2006). Therefore, the accumulation of PBA in the brain could induce toxic effects in lizards.

The PBA level in the faeces was just $0.22 \mathrm{mg} \mathrm{kg}^{-1}$, which was lower than that in any other tissues (Table S5). This result was a total inverse with the concentration of LCT in the faeces, illustrating that the excretion of LCT occurred mainly in the maternal form. PBA, rather than LCT, preferentially accumulated in lizard tissues.

\subsection{Enantioselective bioaccumulation in the liver, fat and skin}

To evaluate the enantiomeric accumulation, the different EF values were calculated in the liver, fat and skin (Fig. 3). The trends of the EF-time curves in these three tissues were similar. According to the results, enantioselective degradation of LCT in the lizards did not follow the same direction at different times. At the beginning of exposure, the EF values were greater than 0.5 , indicating that $(+)$-LCT preferentially accumulated in these tissues. However, the EF value peaked at approximately 0.7 and then rapidly decreased to a level less than 0.5 , which showed that the $(+)$ - LCT was degraded faster at the end of exposure. This was an interesting phenomenon that could be explained by two factors: 1 ) enantiomerization may occur during LCT metabolism and 2) at the beginning of uptake, the accumulation of $(+)$-LCT in the tissues through blood circulation was probably due to the enantioselective intestine absorption of LCT (Takasaki et al., 2005). After that, certain tissue enzymes may play an important role in the further accumulation preference of enantiomers (Gao et al., 2013). This hypothesis could be supported by another paper that showed the value of EF in the plasma was 0.7 , whereas in the liver it was only 0.4 after $30 \mathrm{~min}$ of exposure (Liu et al., 2011). A previous study also investigated the enantioselective accumulation of LCT in human breast milk, which showed a higher accumulation of the (-)-enantiomer (Corcellas et al., 2015a). Corcellas et al. (2015b) also described a general preference for (-)-LCT in the bioaccumulation observed in wild river fish (Corcellas et al., 2015b). The results from these studies suggested that the degradation of LCT in non-target organisms was enantioselective, but the process varied among different species. It could be concluded that higher organisms may have more complicated metabolism processes, and the concentration of (-)-LCT may be enhanced at the end of the exposure period.

\subsection{Histopathology}

The organ coefficient of the liver showed an obvious difference between the treated and control group. In that case, the sub-acute LCT intoxication was assessed histopathologically in hepatic sections. The control group showed a mostly normal liver section; the hepatocytes were polyhedric in shape and comprised of vesicular nuclei and acidophilic cytoplasm (Fig. 4a). The livers of the LCTintoxicated lizards showed disturbed hepatic architecture, shrunken cells with absent nuclei, and narrowed sinusoids (Fig. 4b). Degeneration changes were observed in the vacuolation of cytoplasm (black arrows) and large necrotic areas (circles). The higher incidence of hepatocyte vacuolation in the treated group may be a consequence of lipid and carbohydrate accumulation (AbdelMoneim et al., 2016). This may be a defence mechanism against liposoluble contaminants, although lipid accumulation was
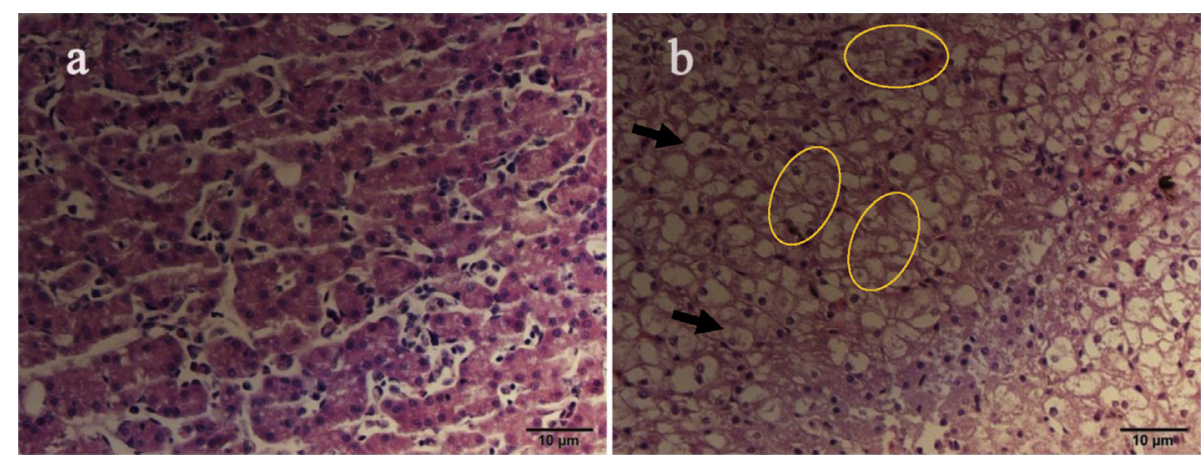

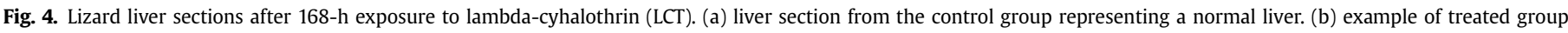
showing vacuolation of cytoplasm (black arrows) and large areas of necrosis (circles). 
regarded as a normal physiological storage (Sylvie et al., 1996). According to some authors, the intensity of vacuolation and necrosis were strongly associated with changes in the liver enzyme activity, which regulated the oxidative stress mechanism and the metabolic rate (Manna et al., 2004; Avci et al., 2005). A previous study also showed histopathological lesions in the liver after treatment with cypermethrin or benalaxyl in lizards (Chen et al., 2016; Wang et al., 2014). In summary, liver histopathology was a useful biomarker that could indicate the toxic effects of contaminants in lizards (Amaral et al., 2012).

\subsection{Relationship between reptile and bird toxicity}

Both historically and currently, birds have been used as surrogates for reptile ecological risk assessment (ERA) (Weir et al., 2015). In the present study, $10 \mathrm{mg} \mathrm{kg}^{-1}$ LCT exposure caused LCT accumulation in the fat, PBA residue in the brain, and significant liver lesions. The effective concentration of LCT in E. argus is 200-fold lower than the $\mathrm{LD}_{50}$ value used for risk assessment in birds. Thus, lizards may be more sensitive to LCT than birds. Our previous study also elucidated that the $7 d-L_{50}$ of several industry chemicals in E. argus were lower than those in Coturnix japonica (Chang et al., 2015). Based on a survey by Weir et al. (2010), only less than $1 / 4$ of the tested chemicals were more toxic to birds than to reptiles (Weir et al., 2010). Therefore, using birds as surrogates in reptile ERA may be not accurate, and further research on reptile ecotoxicology is recommended.

\section{Conclusion}

Lizards have been proposed as ideal model organisms for the risk assessment of reptiles exposed to environmental contaminants (Amaral et al., 2012). The present study elucidated the elimination kinetics of LCT in lizard plasma and tissues after a single oral administration. LCT was rapidly eliminated in the liver, brain, gonads and skin and preferentially accumulated in the fat. The metabolic rate of LCT in the liver was higher than that in other organisms. PBA (one metabolite of LCT) showed bioaccumulation in the brain, which regulated the endocrine system. The enantioselectivity of LCT in lizard tissues was associated with time. Enantiomerization may occur during metabolism, or the elimination preference may vary in the blood and tissues. These hypotheses need further research. During LCT-exposure, the liver was more vulnerable according to HSI changes and histopathological lesions.

\section{Acknowledgment}

The present study was funded by the National Natural Science Foundation of China (Contract Grant number: 41301569, 21277163, 21407170 and 21477152).

\section{Appendix A. Supplementary data}

Supplementary data related to this article can be found at http:// dx.doi.org/10.1016/j.envpol.2016.08.045.

\section{References}

Abdel-Moneim, A.M., Essawy, A.E., Badr El Din, N.K., El Naggar, N.M., 2016 Biochemical and histopathological changes in liver of the Nile tilapia from Egyptian polluted lakes. Toxicol. Ind. Health 32, 457-467.

Aguilera, C., Del Pliego, P.G., Alfaro, R.M., Lazcano, D., Cruz, J., 2012. Pollution biomarkers in the spiny lizard (Sceloporus spp.) from two suburban populations of Monterrey, Mexico. Ecotoxicology 21, 2103-2112.

Al-Sarar, A.S., Abobakr, Y., Bayoumi, A.E., Hussein, H.I., Al Ghothemi, M., 2014 Reproductive toxicity and histopathological changes induced by lambdacyhalothrin in male mice. Environ. Toxicol. 29, 750-762.
Alonso, M.B., Feo, M.L., Corcellas, C., Vidal, L.G., Bertozzi, C.P., Marigo, J., Secchi, E.R., Bassoi, M., Azevedo, A.F., Dorneles, P.R., Torres, J.P.M., Lailson-Brito, J., Malm, O. Eljarrat, E., Barceló, D., 2012. Pyrethroids: a new threat to marine mammals? Environ. Int. 47, 99-106.

Amaral, M.J., Bicho, R.C., Carretero, M.A., Sanchez Hernandez, J.C., Faustino, A.M.R., Soares, A., Mann, R.M., 2012. The use of a lacertid lizard as a model for reptile ecotoxicology studies: Part 2-Biomarkers of exposure and toxicity among pesticide exposed lizards. Chemosphere 87, 765-774.

Anadon, A., Martinez, M., Martinez, M.A., Diaz, M.J., Martinez Larranaga, M.R., 2006. Toxicokinetics of lambda-cyhalothrin in rats. Toxicol. Lett. 165, 47-56.

Anadon, A., Martinezlarranaga, M.R., Diaz, M.J., Bringas, P., 1991. Toxicokinetics of permethrin in the rat. Toxicol. Appl. Pharmacol. 110, 1-8.

Anadon, A., MartinezLarranaga, M.R., FernandezCruz, M.L., Diaz, M.J., Fernandez, M.C., Martinez, M.A., 1996. Toxicokinetics of deltamethrin and its 4'HO-metabolite in the rat. Toxicol. Appl. Pharmacol. 141, 8-16.

Avci, A., Kacmaz, M., Durak, I., 2005. Peroxidation in muscle and liver tissues from fish in a contaminated river due to a petroleum refinery industry. Ecotoxicol. Environ. Saf. 60, 101-105.

Chang, J., Wang, Y., Wang, H., Li, J., Xu, P., 2016. Bioaccumulation and enantioselectivity of type I and type II pyrethroid pesticides in earthworm. Chemosphere $144,1351-1357$.

Chang, J., Yang, S., Dai, X., Li, J., Wang, H., Qu, W., 2015. Toxicity assessment of five chemicals on Eremias argus and Coturnix japonica. Asian J. Ecotoxicol. 10, 276-280.

Chen, L., Xu, P., Diao, J., Di, S., Li, R., Zhou, Z., 2016. Distribution, metabolism and toxic effects of beta-cypermethrin in lizards (Eremias argus) following oral administration. J. Hazard. Mater 306, 87-94.

Chen, W.D., Liang, Y., Xie, L., Lu, T., Liu, X.D., Wang, G.J., 2007. Pharmacokintics of the Ginkgo Bfollowing intravenous administration of Ginkgo B emulsion in rats. Biol. Pharm. Bull. 30, 1-5.

Corcellas, C., Eljarrat, E., Barcelo, D., 2015a. Enantiomeric-selective determination of pyrethroids: application to human samples. Anal. Bioanal. Chem. 407, 779-786.

Corcellas, C., Eljarrat, E., Barcelo, D., 2015b. First report of pyrethroid bioaccumulation in wild river fish: a case study in Iberian river basins (Spain). Environ. Int. 75, 110-116.

Crawford, M.J., Croucher, A., Hutson, D.H., 1981. Metabolism of cis-cypermethrin and trans-cypermethrin in rats-balance and tissue retention study. J. Agric. Food Chem. 29, 130-135.

Deng, W., Lin, D., Yao, K., Yuan, H., Wang, Z., Li, J., Zou, L., Han, X., Zhou, K., He, L., $\mathrm{Hu}, \mathrm{X}$., Liu, S., 2015. Characterization of a novel beta-cypermethrin-degrading Aspergillus niger YAT strain and the biochemical degradation pathway of betacypermethrin. Appl. Microbiol. Biotechnol. 99, 8187-8198.

Ding, Y., White, C.A., Muralidhara, S., Bruckner, J.V., Bartlett, M.G., 2004. Determination of deltamethrin and its metabolite 3-phenoxybenzoic acid in male rat plasma by high-performance liquid chromatography. J. Chromatogr. B 810, $221-227$.

Gao, Y.X., Chen, J.H., Wang, H.L., Liu, C., Lv, X.T., Li, J.Z., Guo, B.Y., 2013. Enantiomerization and enantioselective bioaccumulation of benalaxyl in Tenebrio molitor Larvae from wheat bran. J. Agric. Food Chem. 61, 9045-9051.

Gibbons, J.W., Scott, D.E., Ryan, T.J., Buhlmann, K.A., Tuberville, T.D., Metts, B.S., Greene, J.L., Mills, T., Leiden, Y., Poppy, S., Winne, C.T., 2000. The global decline of reptiles, Deja Vu amphibians. Bioscience 50, 653-666.

Gogebakan, T., Eraslan, G., 2015. Single-dose toxicokinetics of permethrin in broiler chickens. Brit. Poult. Sci. 56, 605-611.

Hao, H., Wang, G., Cui, N., Li, J., Xie, L., Ding, Z., 2007. Identification of a novel intestinal first pass metabolic pathway: NQO1 mediated quinone reduction and subsequent glucuronidation. Curr. Drug Metab. 8, 137-149.

Hirosawa, N., Ueyama, J., Kondo, T., Kamijima, M., Takagi, K., Fujinaka, S., Hirate, A., Hasegawa, T., Wakusawa, S., 2011. Effect of DDVP on urinary excretion levels of pyrethroid metabolite 3-phenoxybenzoic acid in rats. Toxicol. Lett. 203, 28-32.

Huckle, K.R., Chipman, J.K., Hutson, D.H., Millburn, P., 1981. Metabolism of 3phenoxybenzoic acid and the enterohepatorenal disposition of its metabolites in rat. Drug Metab. Disposition 9, 360-368.

Ikemura, K., Urano, K., Matsuda, H., Mizutani, H., Iwamoto, T., Okuda, M., 2009. Decreased oral absorption of cyclosporine A after liver ischemia-reperfusion injury in rats: the contribution of CYP3A and P-glycoprotein to the first-pass metabolism in intestinal epithelial cells. J. Pharmacol. Exp. Ther. 328, 249-255.

Kanazu, T., Okamura, N., Yamaguchi, Y., Baba, T., Koike, M., 2005. Assessment of the hepatic and intestinal first-pass metabolism of midazolam in a CYP3A drugdrug interaction model rats. Xenobiotica 35, 305-317.

Katsuda, Y., 1999. Development of and future prospects for pyrethroid chemistry. Pestic. Sci. 55, 775-782.

Kim, K.B., Bartlett, M.G., Anand, S.S., Kim, H.J., 2006. Rapid determination of the synthetic pyrethroid insecticide, deltamethrin, in rat plasma and tissues by HPLC. J. Chromatogr. B 1, 141-148.

Kim, K.B., Anand, S.S., Kim, H.J., White, C.A., Bruckner, J.V., 2008. Toxicokinetics and tissue distribution of deltamethrin in adult Sprague-Dawley rats. Toxicol. Sci. 101, 197-205.

Kim, K.B., Anand, S.S., Kim, H.J., White, C.A., Fisher, J.W., Tornero Velez, R., Bruckner, J.V., 2010. Age, dose, and time-dependency of plasma and tissue distribution of deltamethrin in immature rats. Toxicol. Sci. 115, 354-368.

Laffin, B., Chavez, M., Pine, M., 2010. The pyrethroid metabolites 3-phenoxybenzoic acid and 3-phenoxybenzyl alcohol do not exhibit estrogenic activity in the MCF-7 human breast carcinoma cell line or Sprague-Dawley rats. Toxicology 267, 39-44. 
Laskowski, D.A., 2002. Physical and chemical properties of pyrethroids. Rev. Environ. Contam. T 174, 49-170.

Leng, G., Gries, W., 2005. Simultaneous determination of pyrethroid and pyrethrin metabolites in human urine by gas chromatography-high resolution mass spectrometry. J. Chromatogr. B 814, 285-294.

Lestremau, F., Willemin, M.E., Chatellier, C., Desmots, S., Brochot, C., 2014. Determination of cis-permethrin, trans-permethrin and associated metabolites in rat blood and organs by gas chromatography-ion trap mass spectrometry. Anal. Bioanal. Chem. 406, 3477-3487.

Li, M.H., Wang, J.S., Lu, Z.G., Wei, D.D., Yang, M.H., Kong, L.Y., 2014. NMR-based metabolomics approach to study the toxicity of lambda-cyhalothrin to goldfish (Carassius auratus). Aquat. Toxicol. 146, 82-92.

Li, W., Zha, J., Li, Z., Yang, L., Wang, Z., 2009. Effects of exposure to acetochlor on the expression of thyroid hormone related genes in larval and adult rare minnow (Gobiocypris rarus). Aquat. Toxicol. 94, 87-93.

Lin, J.H., 2006. Tissue distribution and pharmacodynamics: a complicated relationship. Curr. Drug Metab. 7, 39-65.

Liu, Y., Li, X., Hu, C., Bai, L., 2011. Direct chiral resolution and determination of enantiomeric ratio of lambda-cyhalothrin in rabbits by high-performance liquid chromatography. In: International Conference on Bioinformatics and Biomedical Engineering.

Liu, Y.T., Hao, H.P., Xie, H.G., Lai, L., Wang, Q., Liu, C.X., Wang, G.J., 2010. Extensive intestinal first-pass elimination and predominant hepatic distribution of berberine explain its low plasma levels in rats. Drug Metab. Dispos. 38, 1779-1784.

Manna, S., Bhattacharyya, D., Mandal, T.K., Das, S., 2004. Repeated dose toxicity of alfa-cypermethrin in rats. J. Vet. Sci. 5, 241-245.

McCarthy, A.R., Thomson, B.M., Shaw, I.C., Abell, A.D., 2006. Estrogenicity of pyrethroid insecticide metabolites. J. Environ. Monit. 8, 197-202.

McFarland, C.A., Quinn Jr., M.J., Bazar, M.A., Remick, A.K., Talent, L.G., Johnson, M.S., 2008. Toxicity of oral exposure to 2,4,6-trinitrotoluene in the western fence lizard (Sceloporus occidentalis). Environ. Toxicol. Chem. 27, 1102-1111.

McFarland, C.A., Talent, L.G., Quinn, M.J., Bazar, M.A., Wilbanks, M.S., Nisanian, M., Gogal, R.M., Johnson, M.S., Perkins, E.J., Gust, K.A., 2012. Multiple environmental stressors elicit complex interactive effects in the western fence lizard (Sceloporus occidentalis). Ecotoxicology 21, 2372-2390.

Meyer, E., Eagles-Smith, C.A., Sparling, D., Blumenshine, S., 2014. Mercury exposure associated with altered plasma thyroid hormones in the declining western pond turtle (Emys marmorata) from California mountain streams. Environ. Sci. Technol. 48, 2989-2996.

Nakamura, Y., Sugihara, K., Sone, T., Isobe, M., Ohta, S., Kitamura, S., 2007. The in vitro metabolism of a pyrethroid insecticide, permethrin, and its hydrolysis products in rats. Toxicology 235, 176-184.

Pan, Z., Sai, F., Hong, Z.J., Hong, M., Guang, L.J., Wen, Z.G., Ning, W.Y., 2014. Application of gas chromatography-mass spectrometry in analyzing pharmacokinetics and distribution of deltamethrin in miniature pig tissues. Biomed. Environ. Sci. 426-435.

Perez-Fernandez, V., Angeles Garcia, M., Luisa Marina, M., 2010. Characteristics and enantiomeric analysis of chiral pyrethroids. J. Chromatogr. A 1217, 968-989.

Prueksaritanont, T., Lin, J.H., Baillie, T.A., 2006. Complicating factors in safety testing of drug metabolites: kinetic differences between generated and preformed metabolites. Toxicol. Appl. Pharmacol. 217, 143-152.

Qin, S.J., Budd, R., Bondarenko, S., Liu, W.P., Gan, J.Y., 2006. Enantioselective degradation and chiral stability of pyrethroids in soil and sediment. J. Agric. Food Chem. 54, 5040-5045.

Rutten, A.J., Mather, L.E., McLean, C.F., Nancarrow, C., 1993. Tissue distribution of bupivacaine enantiomers in sheep. Chirality 5, 485-491.

Schumacher, G.E., 1981. Pharmacokinetic concepts and applications affecting the clinical laboratory. Am. J. Med. Technol. 47, 157-161.

Shan, G.M., Huang, H.Z., Stoutamire, D.W., Gee, S.J., Leng, G., Hammock, B.D., 2004.
A sensitive class specific immunoassay for the detection of pyrethroid metabolites in human urine. Chem. Res. Toxicol. 17, 218-225.

Soderlund, D.M., Clark, J.M., Sheets, L.P., Mullin, L.S., Piccirillo, V.J., Sargent, D. Stevens, J.T., Weiner, M.L., 2002. Mechanisms of pyrethroid neurotoxicity: implications for cumulative risk assessment. Toxicology 171, 3-59.

Sparling, D.W., Linder, G., Bishop, C.A., Krest, S.K., 2010. Recent advancements in Amphibian and reptile ecotoxicology. In: Sparling, D.W., Linder, G., Bishop, C.A (Eds.), Ecotoxicology of Amphibians and Reptiles, second ed. SETAC, Pensacola FL, USA, pp. 1-11.

Starr, J.M., Graham, S.E., Ross, D.G., Tornero Velez, R., Scollon, E.J., DeVito, M.J. Crofton, K.M., Wolansky, M.J., Hughes, M.F., 2014. Environmentally relevant mixing ratios in cumulative assessments: a study of the kinetics of pyrethroids and their ester cleavage metabolites in blood and brain; and the effect of a pyrethroid mixture on the motor activity of rats. Toxicology 320, 15-24.

Sun, H., Chen, W., Xu, X., Ding, Z., Chen, X., Wang, X., 2014. Pyrethroid and their metabolite, 3-phenoxybenzoic acid showed similar (anti) estrogenic activity in human and rat estrogen receptor alpha-mediated reporter gene assays. Environ. Toxicol. Pharmacol. 37, 371-377.

Suski, J.G., Salice, C., Houpt, J.T., Bazar, M.A., Talent, L.G., 2008. Dose-related effects following oral exposure of 2,4-dinitrotoluene on the western fence lizard, Sceloporus occidentalis. Environ. Toxicol. Chem. 27, 352-359.

Sylvie, B.R., Pairault, C., Vernet, G., Boulekbache, H., 1996. Effect of lindane on the ultrastructure of the liver of the rainbow trout, Oncorhynchus mykiss, sac-fry. Chemosphere 33, 2065-2079.

Takasaki, W., Yamamura, M., Nozaki, A., Nitanai, T., Sasahara, K., Itoh, K., Tanaka, Y. 2005. Stereoselective pharmacokinetics of RS-8359, a selective and reversible MAO-A inhibitor, by species-dependent drug-metabolizing enzymes. Chirality 17, 135-141.

Tsai, P.L., Tsai, T.H., 2004. Hepatobiliary excretion of berberine. Drug Metab. Disposition 32, 405-412.

Tu, W.Q., Lu, B., Niu, L.L., Xu, C., Lin, C.M., Liu, W.P., 2014. Dynamics of uptake and elimination of pyrethroid insecticides in zebrafish (Danio rerio) eleutheroembryos. Ecotoxicol. Environ. Saf. 107, 186-191.

Wagner, N., Mingo, V., Schulte, U., Loetters, S., 2015. Risk evaluation of pesticide use to protected European reptile species. Biol. Conserv. 191, 667-673.

Walker, C.H., Ronis, M.J.J., 1989. The monooxygenases of birds, reptiles and amphibians. Xenobiotica 19, 1111-1121.

Wang, L.M., Liu, W., Yang, C.X., Pan, Z.Y., Gan, J.Y., Xu, C., Zhao, M.R., Schlenk, D., 2007. Enantioselectivity in estrogenic potential and uptake of bifenthrin. Environ. Sci. Technol. 41, 6124-6128.

Wang, Y., Guo, B., Gao, Y., Xu, P., Zhang, Y., Li, J., Wang, H., 2014. Stereoselective degradation and toxic effects of benalaxyl on blood and liver of the Chinese lizard Eremias argus. Pestic. Biochem. Physiol. 108, 34-41.

Weir, S.M., Suski, J.G., Salice, C.J., 2010. Ecological risk of anthropogenic pollutants to reptiles: evaluating assumptions of sensitivity and exposure. Environ. Pollut. 158, 3596-3606.

Weir, S.M., Talent, L.G., Anderson, T.A., Salice, C.J., 2014. Unraveling the relative importance of oral and dermal contaminant exposure in reptiles: insights from studies using the western fence lizard (Sceloporus occidentalis). PLoS One 9.

Weir, S.M., Yu, S., Talent, L.G., Maul, J.D., Anderson, T.A., Salice, C.J., 2015. Improving reptile ecological risk assessment: oral and dermal toxicity of pesticides to a common lizard species (Sceloporus occidentalis). Environ. Toxicol. Chem. 34 1778-1786.

Yao, G., Jing, X., Peng, W., Liu, X., Zhou, Z., Liu, D., 2015. Chiral insecticide alphacypermethrin and its metabolites: stereoselective degradation behavior in soils and the toxicity to earthworm Eisenia fetida. J. Agric. Food Chem. 63, 7714-7720.

Zhang, P., Zhu, W., Qiu, J., Wang, D., Wang, X., Wang, Y., Zhou, Z., 2014. Evaluating the enantioselective degradation and novel metabolites following a single oral dose of metalaxyl in mice. Pestic. Biochem. Physiol. 116, 32-39. 